\title{
Failure Analysis of Stainless Steel Lanyard Wire Rope
}

\author{
Aginaparru Sambasiva Rao and Ashok Kumar Singh

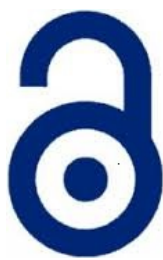 \\ Received: 26 June 2018 \\ Accepted: 21 July 2018 \\ Published: 15 September 2018 \\ Publisher: Deer Hill Publications \\ (c) 2018 The Author(s) \\ Creative Commons: CC BY 4.0
}

\begin{abstract}
Present work describes the failure analysis of AISI 304 stainless steel lanyard wire rope which has failed during application in humid atmosphere. The wire rope has $7 \times 19$ construction which means that it consists of seven strands and each strand having 19 wires twisted in a helical fashion. The microstructures and properties of failed wire rope have been investigated and compared with unused wire rope. Both the periphery and fracture surface of the wire rope display the presence of corrosion debris enriched with $\mathrm{O}$ and $\mathrm{Cl}$. The fracture surfaces of the failed and unused wire ropes display intergranular and dimples, respectively. The lanyard wire rope has been exposed in corrosive atmosphere and failed in intergranular mode due to enrichment of $\mathrm{O}$ and $\mathrm{Cl}$ along the grain boundaries.
\end{abstract}

Keywords: Lanyard wire rope, Stainless steel, EPMA, Intergranular corrosion

\section{INTRODUCTION}

Lanyard wire ropes or cable assemblies are cables comprised of many spiralled bundles of wire. These wire ropes have connector at each end for connecting the body support to fall arrestor, energy absorber, anchorage connector or anchorage [1]. This covers a very broad range of wire rope products, and wire rope lanyards can be extensively customized to meet the needs of a multitude of applications. These are commonly used in security, holding, hanging, attaching, anchoring, lifting, supporting and pulling. The wire ropes have been designed for specific purpose depending on a particular application [2]. Wire rope consists of multiple strands of wire filament which themselves are twisted together before being wound helically around a core. The number of each set of strands depends on the strength requirements for proposed application [3]. The construction of lanyard wire rope is defined as $n \times p$ where $n$ and $p$ are number of strands and number of wires in each strand, respectively [2]. A common lanyard wire rope is represented by as $7 \times 19$ construction which suggests that this is made up of nineteen small wires being twisted together with seven other similar bundles [4].

Among all other materials, stainless steel lanyard is usually found in unique work areas. Apart from the other features, high strength, excellent abrasion resistance and corrosion resistance are the most important characteristics [1]. Stainless steels are used in corrosive environment particularly in area of petrochemical industries and humid atmosphere [5]. These wires are also coated with different plastic materials to enhance both the functional as well as appearance. The major defects in wire ropes are by and large due to oxidation, corrosion, excessive heat, chemical degradation etc. [6]. In addition, environmental condition particularly humid atmosphere containing seawater also initiates the degradation of wire ropes. It is to be noted that the seawater contains chlorine that corrodes the metals in general and stainless steel in particular [7]. Nonetheless, all the wire ropes fail in the zone which has been subjected to highest amount of fatigue and abrasion [8-12]. The present work is thus concerned with the failure analysis of a $7 \times 19$ construction lanyard wire rope which has failed during application in humid atmosphere. The microstructure and properties of unused wire has also been investigated and compared with the failed rope.

\section{EXPERIMENTAL}

Initially, visual examinations of the broken lanyard wire rope were carried out and the photographs of the failed wire rope were captured using digital camera. The chemical composition of wire rope was analysed using Inductively Coupled Plasma Optical Emission Spectroscopy (ICP-OES) and given in Table 1. The interstitial elements such as $C$ and $S$ were measured using inert gas fusion technique.

\section{A. S. Rao' and A. K. Singh ${ }^{2} \otimes$}

Materials Science Division, Defence Metallurgical Research Laboratory

Defence Research \& Development Organization, Kanchanbagh, Hyderabad, 5000258 India

'E-mail: sivadmrl@gmail.com, 2E-mail: singh_ashok3@rediffmail.com 
Table 1: Chemical composition of the failed wire rope.

\begin{tabular}{l|ccccccc}
\hline Element & $\mathrm{C}$ & $\mathrm{S}$ & $\mathrm{Ni}$ & $\mathrm{Cr}$ & $\mathrm{Mn}$ & $\mathrm{Si}$ & $\mathrm{Fe}$ \\
\hline Wt.\% & 0.08 & 0.002 & 8.2 & 19.7 & 1.8 & 0.92 & Balance \\
\hline
\end{tabular}

It suggests that the material used for wire rope is austenitic stainless steel and conforms to AISI 304 grade. Wires were cut from the failed wire rope near the actual fractures and prepared for metallographic examination. The polished surface was etched with aquaregia $\left(50 \% \mathrm{HCl}\right.$ and $50 \% \mathrm{HNO}_{3}$ by volume). Microstructural characterization was done using optical microscope (ASTM E-4). The failed wires at the fractured surface were separated from the long wire rope and then bound together with a copper wire. These wires were cleaned ultrasonically in acetone to remove any dirt and other lubricant residues over the fracture surface. The fracture surfaces of the multiple wire failed sections near actual fracture were examined under a FEl make environmental scanning electron microscope (Model: Quanta 400) to evaluate the contaminated products over the fracture surface as well as mode of fracture.

As received failed rope, wires were further examined using Electron Probe Micro Analyser (EPMA) to study the grain boundary constituents that have caused the degradation of microstructure. Samples were prepared as per metallographic examination and analysed in un-etched condition for EPMA examination. Back scattered electron (BSE) image, elemental distribution mapping and line profile for different elements were analysed using CAMECA make, SX-100 model EPMA. Quantitative analysis was carried out with an operating voltage of $20 \mathrm{kV}$ and with a stabilized beam current of $20 \mathrm{nA}$. A LiF (Lithium Fluoride) crystal was employed to diffracting Ti K $\alpha, \mathrm{Mn} \mathrm{K} \alpha$ and Ni $\mathrm{K} \alpha$; PET (Pentaerythritol) crystal was used for diffracting $\mathrm{Cr} \mathrm{K} \alpha, \mathrm{Mo} \mathrm{L} \alpha, \mathrm{V} \mathrm{K} \alpha, \mathrm{Nb} \mathrm{K} \alpha$ and $\mathrm{Cl} \mathrm{K} \alpha$ and TAP (Thallium Acid Phthalate) crystal was employed for diffracting Si K $\alpha$ X-ray lines. Pseudocrystals of PC2 having $2 d$ value of 98 $\AA$ was utilized for Oxygen analysis. X-ray intensities were obtained both on respective pure metallic standards and on samples with identical operating conditions. Absolute elemental concentrations were attained using built in analytical software with essential ZAF correction to get accurate weight/atom percentage of constituents in the respective sample.

Wire rope strands were separated from the rope and cut to desired length for tensile testing. Tensile properties of failed, used (but not failed) and unused wire ropes were evaluated to know the maximum load bearing capacity. Room temperature tensile tests (ASTM E8) were conducted with a strand containing 19 wires on screw driven Instron (5500 R) testing machine (Instron Corporation, Norwood, MA). Three specimens were tested in each wire rope and average values are reported in Table 2. Fracture surfaces of tensile specimens were again examined under environmental scanning electron microscope (SEM: FEI Quanta 400).

\section{RESULTS}

The broken wire rope in as-received condition is shown in Figs.1 (a-c). Wire rope is made up of seven strands and each strand comprises 19 wires (rope length: 3 feet 6 inches). This displays dark brownish colour. The wire rope supplied with two broken ends (Fig. 1a). This consists of many small diameter wires wound together into strands and then these strands are knit jointly into a wire rope. The end fittings of the wire rope are festinated with open swaged socket. Broken end region displays several wires unwound and loosen from their strands (Fig.1 b, c).

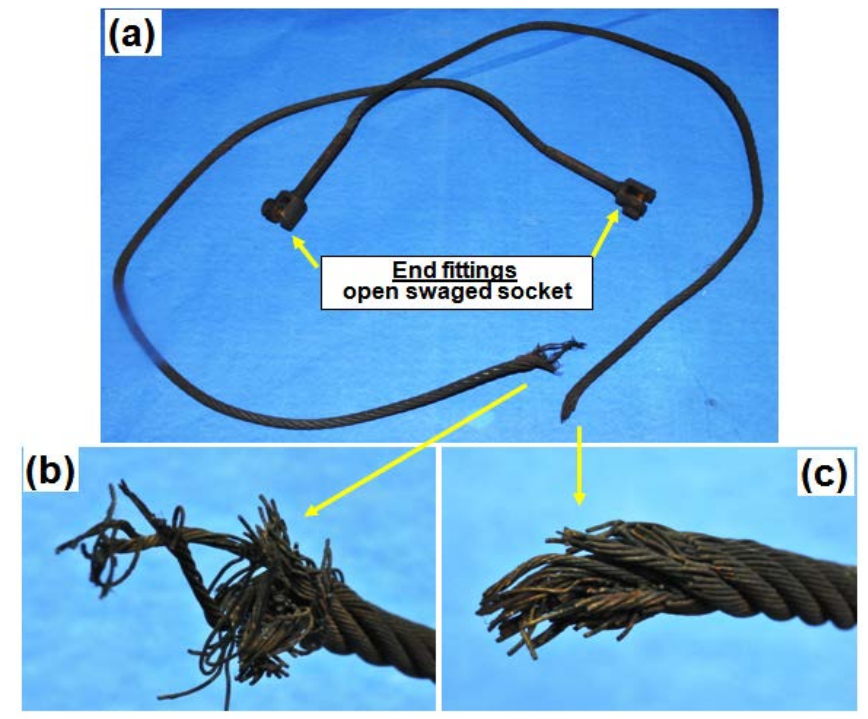

Figure 1: Photograph of failed wire rope: (a) as-received condition, (b) one end of the broken rope, (c) another end of the broken rope displays several wires unwound from its strands and loosens from their strands. 
Optical microstructures of the wire rope are shown in Fig. 2. This displays the presence of typical equaixed austenitic grains along with annealing twins (Fig. 2a). The grain size near and away from failed appears to be same. Very close to the fractured area, the microstructure exhibits extensive material degradation due to grain boundary weakening. The several pieces of material consisting of a few grains are dislodged from the periphery of the individual broken wire by breaking along grain boundaries (Figs. 2b). BSE image close to the fracture obtained in un-etched condition exhibits continuous thin film along grain boundaries (Fig. 3). This observation is analogue to the optical microstructure (Fig. 2). The X-ray elemental mappings of $\mathrm{O}, \mathrm{Cl}, \mathrm{Cr}, \mathrm{Ni}$ and $\mathrm{Mn}$ elements of failed wire rope in un-etched condition obtained by EPMA are shown in Fig. 4 (a-f). Elemental distribution mapping reveals that the grain boundaries are enriched with Oxygen, Chlorine and Chromium Fig. 4 (b-d). On the other hand, uniform distributions of Nickel and Manganese are observed in the matrix Fig. 4 (e-f).

In order to confirm these results, X-ray line scan technique has been employed for Oxygen Chlorine and Chromium elements and results are shown in Fig. 5. This reflects evidently that the line scan profiles have validated the enrichment of Oxygen, and Chlorine at the grain boundary. Line profile has also displayed the chromium enrichment at the grain boundary as well as the depletion at either side of the grain (i.e. at the vicinity of grain boundary). The fracture surfaces of failed wire rope near the actual fractures are shown in Figs. 6 (a-d). Thick layer of foreign material deposition is exhibited over the fracture surface of the individual wires and all around the surface of each wire. The fracture surfaces of the wire appear to be rough and the individual wire does not show distinctive mode of fracture features. These are similar to mud cracks with oxide layer (Fig. 6 b-d).
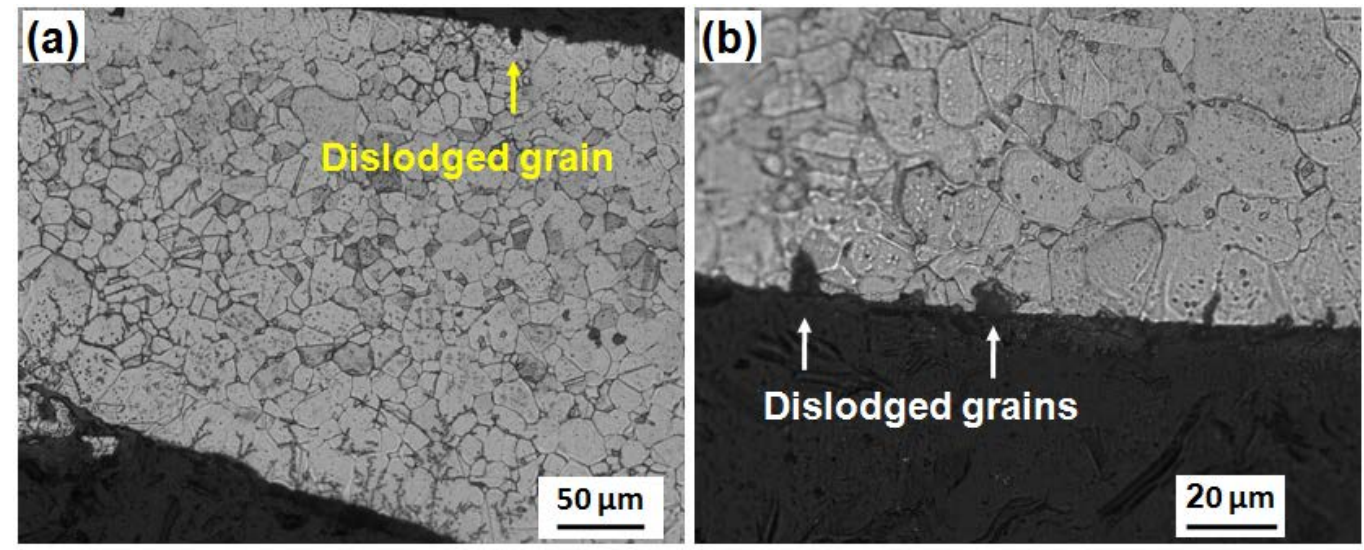

Figure 2: Optical micrograph of failed wire rope shows (a) austenite grain structure with few dislodged grains from the grain boundaries at the surface near fracture and (b) high magnification of Figure a.

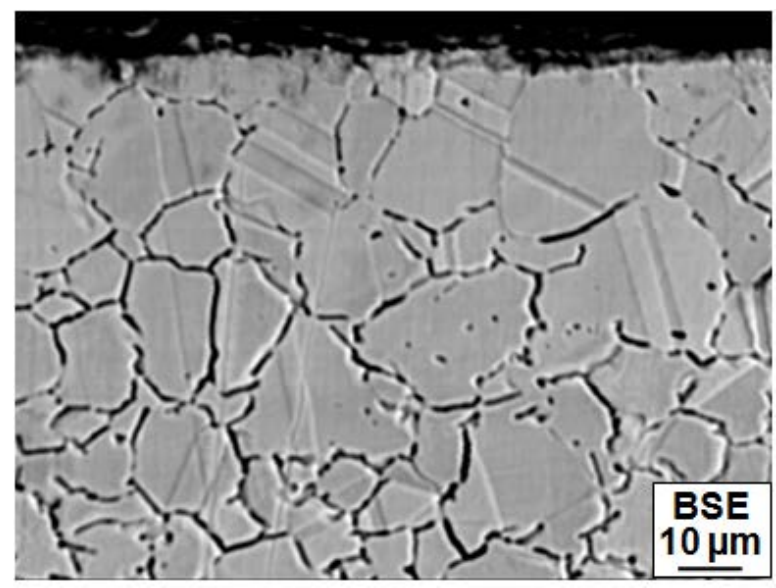

Figure 3: BSE microstructure of the individual wire near failed end showing dislodged grain structure at the surface and dark network along grain boundaries. 


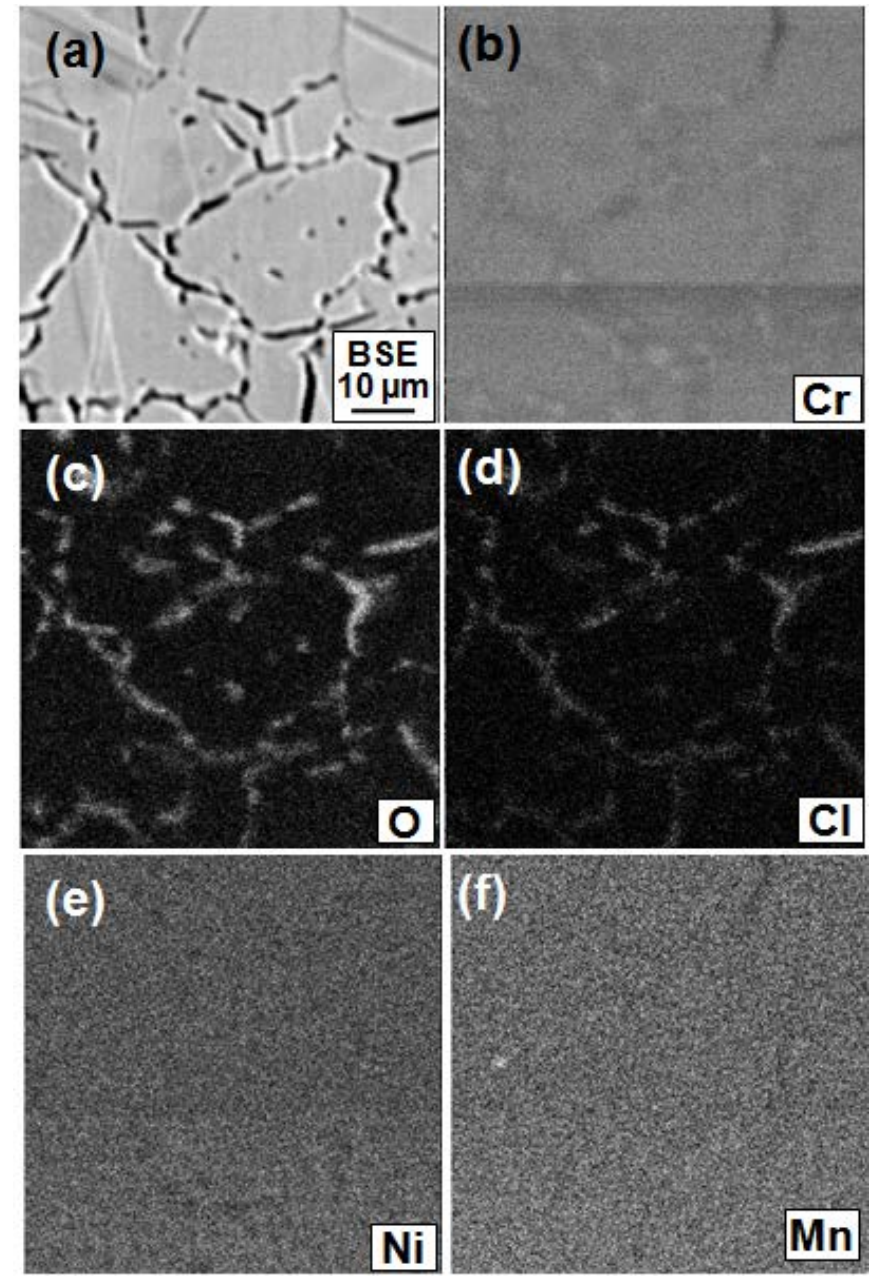

Figure 4: (a) BSE micrograph and X-ray elemental distribution mappings: (b) $\mathrm{Cr}$, (c) $\mathrm{O}$, (d) $\mathrm{Cl}$, (e) $\mathrm{Ni}$ and (f) $\mathrm{Mn}$ obtained by EPMA technique.

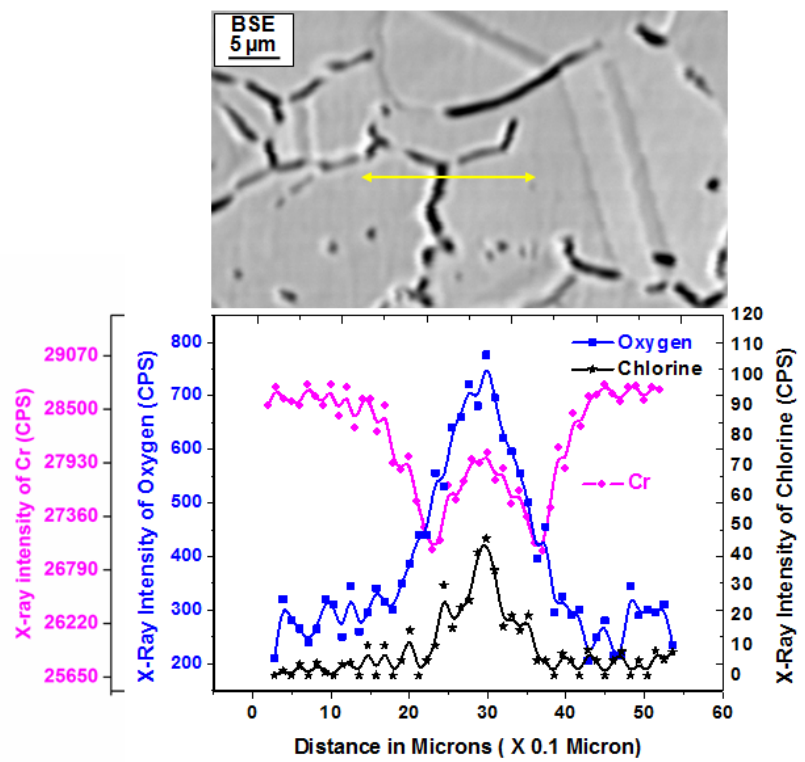

Figure 5: EPMA Line profile of the elements $\mathrm{O}, \mathrm{Cl}$ and $\mathrm{Cr}$ across the grain boundary demonstrates as reflected in the X-ray mappings. 
EDAX spectrum taken on fracture surface of the failed rope near the actual fractures has revealed the presence of chlorine and oxygen in addition to matrix elements (Fig. 7). These results are well agreement with those obtained by EPMA analysis (Fig. 4 and 5). Tensile properties of failed, used (but not failed) and unused wire ropes are summarized in Table 2. It clearly shows that the load bearing capacity of the failed wire has reduced nearly $1 / 4$ and $1 / 2$ times of the unused and used wires, respectively. The ultimate tensile strengths of the wires reported in Table 2 also support the same. The fracture surfaces of tensile tested specimens of the failed and unused wires are shown in Figs. 8 and 9. The flat fracture with no reduction in the cross sectional area is seen in the failed individual wire (Fig. $8 \mathrm{a})$.
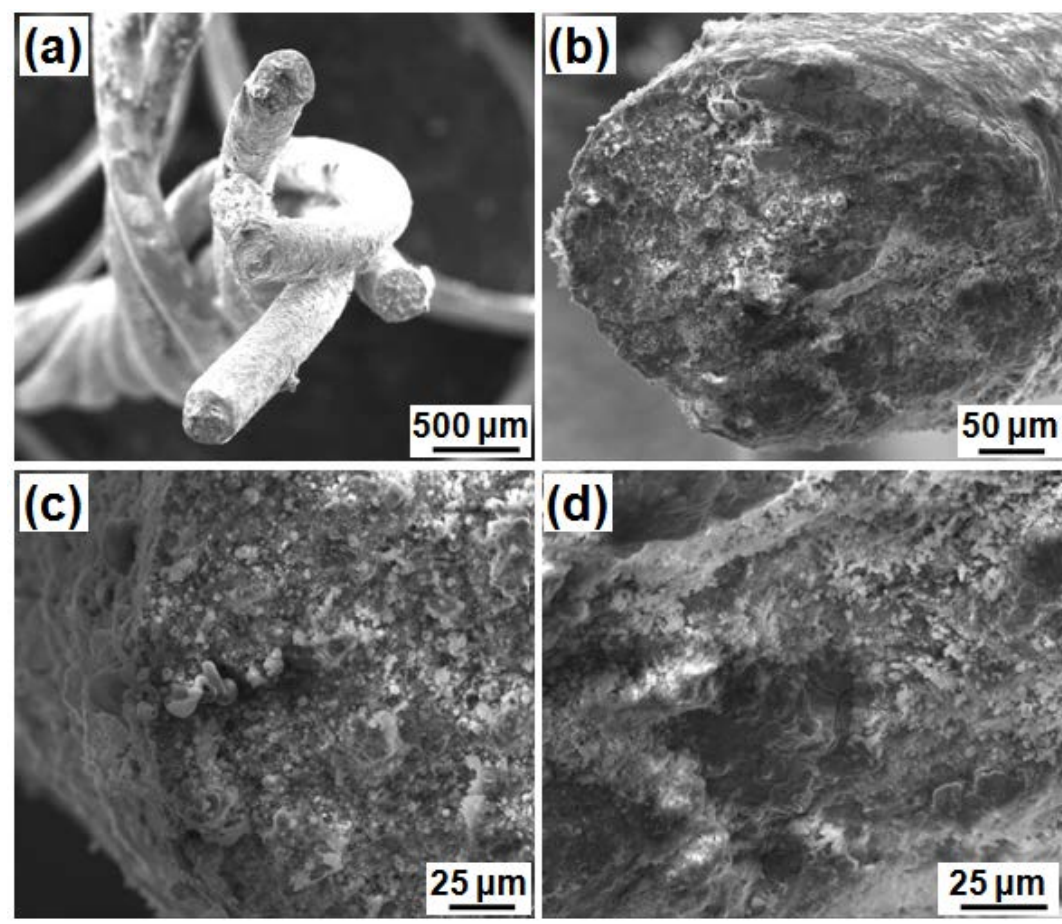

Figure 6: SEM fractographs of individual failed wire obtained at (a) Low magnification and (b-d) high magnification show thick layer deposition of corrosion debris over the fracture surface.

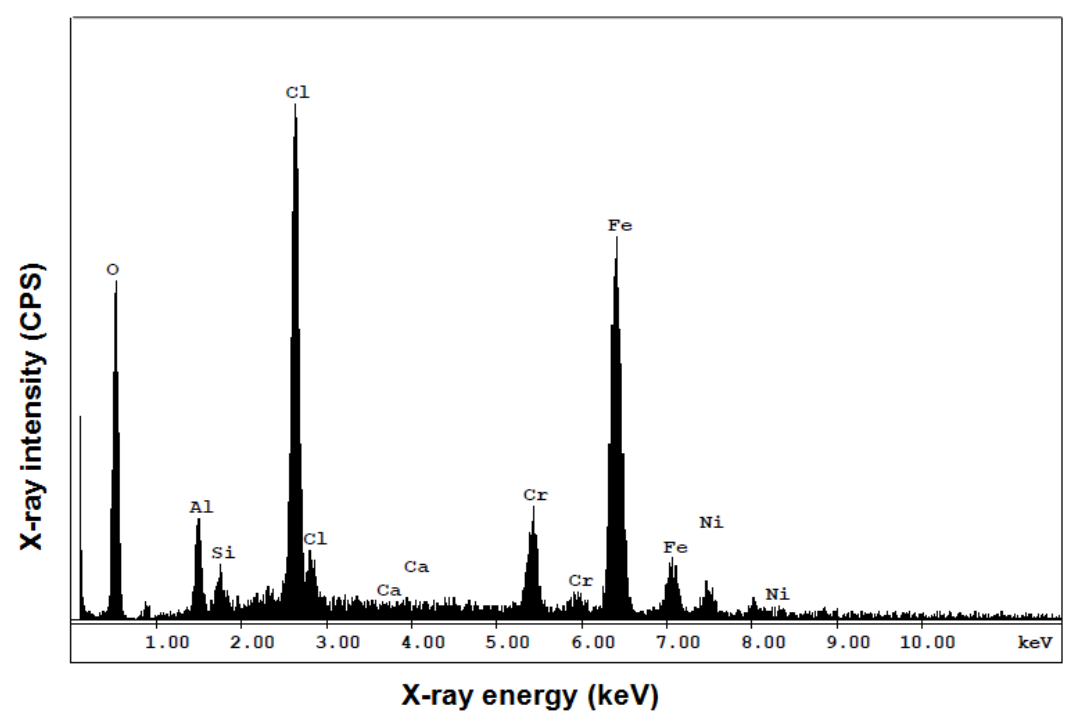

Figure 7: EDAX Spectrum taken from the fracture surface of the failed individual wire exhibits presence of $\mathrm{O}$ and $\mathrm{Cl}$ in addition to matrix elements. 
Fracture surface of tensile tested wire of the failed rope displayed a thick metallic layer covered around the circumference of the failed wire. However, a part of the thick layer of the individual wire has fallen away from close to tensile fracture during tensile deformation (Fig. 8a). The fracture surface of the wire appears to be rough and clearly reveal the presence of intergranular fracture (Figs. 8 ( $c$ and $\mathrm{d}$ )). The tensile fracture surface of the unused wire exhibits smooth surface finish around the rope outer surface (Fig. 9a). The fracture features displays sufficient necking indicating typical ductile mode of failure (Fig. 9b).

Table 2: Tensile properties of the strands for unused, used (not failed) and failed wire ropes.

\begin{tabular}{clcc}
\hline SI. No. & \multicolumn{1}{c}{ Description } & $\begin{array}{c}\text { Max. Tensile Breaking } \\
\text { Load (kN) }\end{array}$ & $\begin{array}{c}\text { UTS } \\
\text { (MPa) }\end{array}$ \\
\hline 1. & Strand from Unused Wire Rope & 3.00 & 1490 \\
2. & Strand from used (not failed) Wire Rope & 1.35 & 685 \\
3. & Strand from Failed Wire Rope & 0.70 & 378 \\
\hline
\end{tabular}
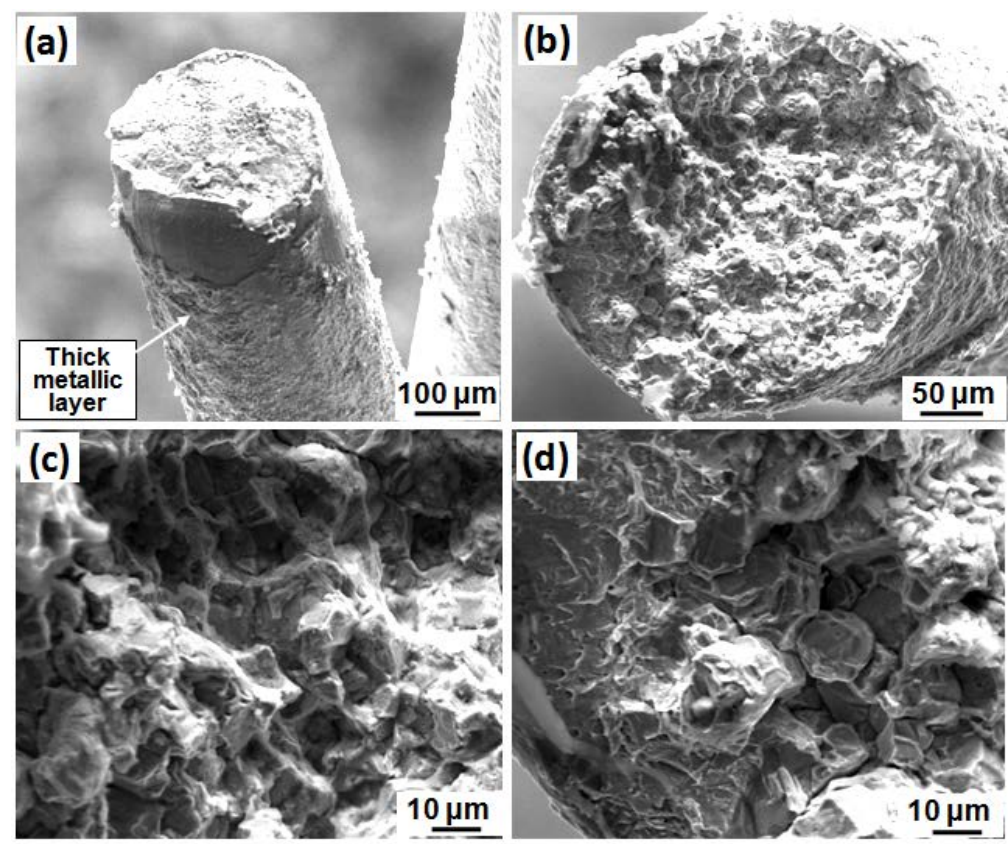

Figure 8: SEM fractographs of tensile tested failed wire rope: (a) low magnification and (b-d) High magnification reveals flat fracture with intergranular mode of failure.
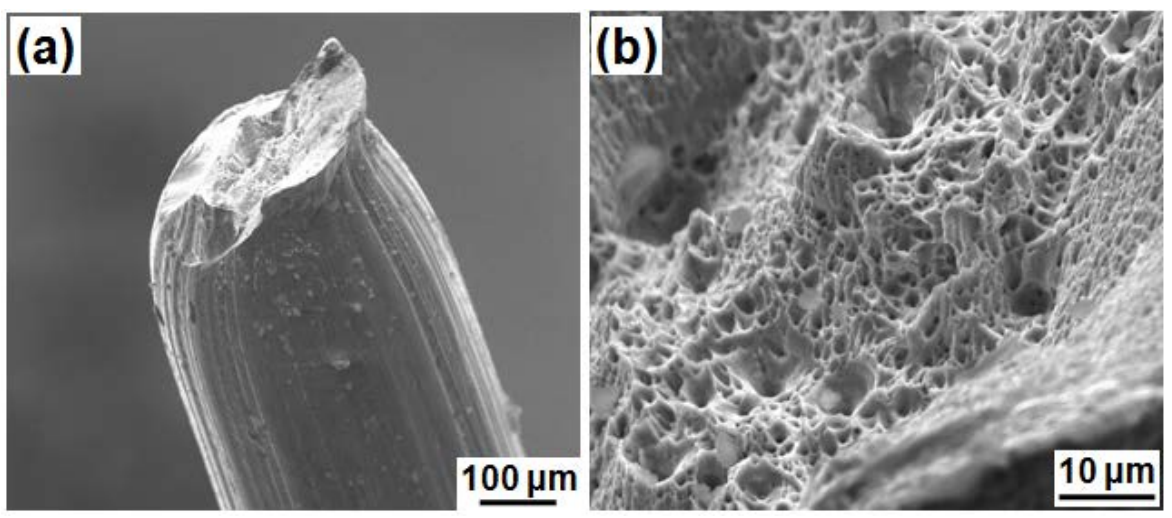

Figure 9: SEM fractographs of tensile tested unused wire rope: (a) low magnification (b) high magnification showing considerable reduction in size with dimple mode of fracture. 


\section{DISCUSSIONS}

Chemical composition of the wire rope indicates that the wires are made using austenitic stainless steel AISI 304 grade (Table 1). Presence of annealing twins within the equiaxed austenitic grains indicates that the wire rope is used in annealed condition (Fig. 2a). This also suggests that the rope wires are initially prepared by wire drawing and subsequently annealed. The optical microstructure of the wire exhibits two features namely (a) overall grain size is nearly uniform from centre to periphery and (b) several cracks along the grain boundaries at the periphery of the wire rope. In addition, parts of material consisting of several grains have been dislocated from the wire (Figs. 2 b). The dislocated materials have broken from the wire along the grain boundaries. This clearly reveals that that the grain boundaries have significantly weakened during service.

The BSE micrograph of un-etched samples resembles similar features to that of the optical microstructure. EPMA $X$-ray elemental mappings reflect that grain boundaries are enriched with $\mathrm{Cl}, \mathrm{O}$ and $\mathrm{Cr}$ (Fig. 4). The weakening of grain boundaries along with dislodged materials from the periphery of the wire therefore indicates that the rope is exposed to corrosive environment during the service. Presence of $\mathrm{Cl}$ and $\mathrm{O}$ at the grain boundaries in the form of thin film supports the same. In addition, the periphery of the individual wire is also surrounded by thick continuous layer of the corrosive debris (Fig. 6 a-d). Fracture surfaces of the failed rope have shown the presence of corrosion debris which in fact has masked the actual fracture (Fig. 6). The EDAX spectrum of the fracture surface also supports the presence of $\mathrm{Cl}$ and $\mathrm{O}$ (Fig. 7). All the wires in the failed rope have shown similar behaviour.

The results of the tensile tests of the used (but not failed) and unused wires have been utilized to explain the occurrence of typical fracture features of the failed wire rope. Fascinatingly, the load bearing capacity of the failed wire has reduced to nearly $1 / 4$ of the unused wire rope (Table 2). The used (but not failed) wire on the other hand also displays reduction in breaking load nearly half of unused wire rope. This also reflects that the properties of the rope have deteriorated significantly during service.

Tensile tested fracture surfaces of the unused wires display entirely different features (Fig. 9) than that of the failed wires in terms of mode of failure (Fig. 8). The failed wire exhibits typical intergranular fracture in spite of the presence of corrosive debris. In addition, this also shows the presence of thick layers around the periphery (Fig. 8a). On the other hand, fracture surfaces of unused wire rope exhibits smooth surface finish around the rope outer surface (Fig. 9a). Unused wire rope has undergone significant necking before tensile failure and finally failed in ductile mode. This clearly suggests that the wire rope has slowly deteriorated during service and then suddenly failed with intergranular fracture mode. It appears that the crack propagated along the weak grain boundaries during tensile test and finally failed in intergranular mode (Fig. 8).

When passive metals such as the stainless steels corrode, the corrosion develops where passivity has been destroyed. If there are halogenides such as chlorides present in the environment, these can interact with passive film locally and break it by introducing small isolated spots [13-14]. This is also termed as pitting corrosion. This type of corrosion is likely due to chlorine-induced pitting of the stainless steel material from the chloride containing humid environment. The chlorides can then react with chromium to form soluble chromium chloride following $\left(\mathrm{CrCl}_{3}\right)$ $2 \mathrm{Cr}+3 \mathrm{Cl}_{2}=2 \mathrm{CrCl}_{3}$ reaction. As a result, $\mathrm{Cr}$ at the grain boundaries is partly dissolved leaving only the corrosion prone iron [15]. This also introduces depletion of $\mathrm{Cr}$ in neighbouring area of the grain boundaries which are prone to fail in intergranular mode (Figs. 5 and 8).

The occurrence of intergranular corrosion has also been reported even without the chromium carbide precipitates at the grain boundaries [16]. This has been attributed to high energy associated with the grain boundaries which are preferentially corroded (become anode) due to their low electrode potential in comparison to grain interior. The present lanyard rope has also failed in intergranular mode due to the formation of $\mathrm{CrCl}_{3}$ in presence of humid environment.

As mentioned above, microstructure of the failed wire rope exhibits thin film at the grain boundaries consisting of $\mathrm{O}$ and $\mathrm{Cl}$ along with the dislodged materials containing a few grains. It appears that the presence of both the high $\mathrm{O}$ and $\mathrm{Cl}$ at the grain boundaries can be ascribed to corrosive atmosphere. The chlorine ions from the water content / vapours from humid atmosphere have initially reacted with chromium oxide passive film formed on the surface of the wire and then diffused within the material along the grain boundaries. The depletion of the $\mathrm{Cr}$ in vicinity of the grain boundaries supports the same (Fig. 5). This has resulted in the failure of the wire rope in intergranular mode due to substantial weakening of grain boundaries.

\section{CONCLUSIONS}

1. The failed wire rope near the actual fracture region consists of large amount of oxygen and chlorine which have served as initiation sites for cracks in the material.

2. The load bearing capacity of the failed wire rope strand has significantly reduced to nearly $1 / 4$ times to that of the new unused wire rope in identical testing conditions.

3. Fracture surfaces of tensile tested used and unused lanyard rope individual wires have shown intergranular and ductile dimple modes of fracture, respectively.

4. The lanyard wire rope has been exposed in corrosive atmosphere and failed in intergranular mode due to enrichment of $\mathrm{O}$ and $\mathrm{Cl}$ along the grain boundaries. 


\section{ACKNOWLEDGEMENTS}

The authors wish to acknowledge Defence Research and Development Organization for financial support. We are grateful to Dr. Vikas Kumar, Director, Defence Metallurgical Research Laboratory for his kind encouragement. Authors also thank Electron Microscopy, Structure and Failure Analysis and Mechanical Behaviour Groups of DMRL for their kind help.

\section{REFERENCES}

1. Baszczyński, K. (2007). Dynamic strength tests for low elongation lanyards. International Journal of Occupational Safety and Ergonomics, 13(1), 39-48.

2. Costello, G. A. (1990). Theory of wire rope. Chapter 1. Mechanical engineering series, 2nd edition. New York.

3. Chaplin, C. R. (1995). Failure mechanisms in wire rope. Engineering failure analysis, 2(1), 45-57.

4. Davis, G. J. (1997). Wire rope user's manual. Chapter 3. Committee of wire rope producers, American Iron and Steel Institute. Washington.

5. Parrott, R. and Pitts, H. (2011). Chloride stress corrosion cracking in austenitic stainless steel. Chapter 1. Research report RR902. Health and safety executive laboratory.

6. Ren, Z., Lu, Z., Yu, Q. and Jiang, Y. (2018). Failure analysis and safety protection of a certain type of wire rope under high-speed impact loads. MATEC Web Conf., Int. Conf. on Materials applications and Engineering, 142, 03001, 1-8. (DOI: https://doi.org/10.1051/matecconf/201814203001).

7. Brown, B. F. (1977). Stress corrosion cracking control measures, Chapter 7. National bureau of standards monograph 156.

8. Schrems K. K. (1994). Wear-related fatigue in a wire rope failure, Journal of testing and evaluation, 22(5), 490490.

9. Balan K. P. (2002). Failure analysis of a wire rope, Practical failure analysis, 2(3), 71-74.

10. Torkar, M., Arzenšek, B. (2002). Failure of crane wire rope, Engineering Failure Analysis, 9, 227-233.

11. Pal, U., Mukhopadhyay, G., Sharma, A. and Bhattacharya, S. (2018). Failure analysis of wire rope of ladle crane in steel making shop. International Journal of Fatigue, 116, 149-155.

12. Kalentev, E., Václav, S., Božek, P., Tarasov, V. and Korshunov, A. (2017). Numerical analysis of the stress-strain state of a rope strand with linear contact under tension and torsion loading conditions. Advances in Science and Technology Research Journal, 11(2), 231-239. DOI: 10.12913/22998624/71181.

13. Bensalah N. (2012). Pitting Corrosion. Chapter 7, Corrosive effects of chlorides on metals, Fong-Yuan Ma.

14. Leffler B. (1998). Stainless-stainless steels and their properties. Chapter 3. $2^{\text {nd }}$ edition.

15. Tverberg, J. C. (2001). Stainless steel in the brewery. MBAA TQ. Technical Quarterly, 38(2), 67-82.

16. Kodgire, V. D. \& Kodgire, S. V. (2013). Material science and metallurgy for engineers. Chapter $6.32^{\text {nd }}$ edition. 